\title{
Control Technology for Radioactive Emissions to the Atmosphere at U.S. Department of Energy Facilities: The Los Alamos Meson Physics Facility
}
E. B. Moore
H. T. Fullam

March 1985

Prepared for the Eastern Environmental Radiation Facility U.S. Environmental Protection Agency Montgomery, Alabama

Pacific Northwest Laboratory Operated for the U.S. Department of Energy by Battelle Memorial Institute 


\title{
DISCLAIMER
}

This report was prepared as an account of work sponsored by an agency of the United States Government. Neither the United States Government nor any agency thereof, nor any of their employees, makes any warranty, express or implied, or assumes any legal liability or responsibility for the accuracy, completeness, or usefulness of any information, apparatus, product, or process disclosed, or represents that its use would not infringe privately owned rights. Reference herein to any specific commercial product, process, or service by trade name, trademark, manufacturer, or otherwise, does not necessarily constitute or imply its endorsement, recommendation, or favoring by the United States Government or any agency thereof. The views and opinions of authors expressed herein do not necessarily state or reflect those of the United States Government or any agency thereof.

\author{
PACIFIC NORTHWEST LABORATORY \\ operated by \\ BATTELLE \\ for the \\ UNITED STATES DEPARTMENT OF ENERGY \\ under Contract DE-AC06-76RLO 1830
}

Although the research described in this article has been funded wholly or in part by the United States Environmental Protection Agency (EPA), it has not been subjected to EPA review and therefore does not necessarily reflect the views of EPA and no official endorsement should be inferred. 
CONTROL TECHNOLOGY FOR RADIOACTIVE EMISSIONS TO THE ATMOSPHERE AT U.S. DEPARTMENT OF ENERGY FACILITIES: THE LOS ALAMOS MESON PHYSICS FACILITY

E. B. Moore

H. T. Fullam

March 1985

Prepared for the Eastern Environmental Radiation Facility U.S. Environmental Protection Agency Montgomery, Alabama

Under a Related Services Agreement

Contract DE-AC06-76RLO 1830

Pacific Northwest Laboratory

Richland, Washington 99352 
: 


\section{FOREWORD}

The U.S. Environmental Protection Agency (EPA) has authority under the Clean Air Act as amended to set standards for the emission of radionuclides into the atmosphere from U.S. Department of Energy (DOE) facilities. As part of EPA's rulemaking proceedings, the Pacific Northwest Laboratory (PNL) prepared the following document:

Control Technology for Radioactive Emissions to the Atmosphere at U.S. Department of Energy Facilities, E. B. Moore, Project Manager, PNL-4621 Final, prepared for the U.S. Environmental Protection Agency

by the Pacific Northwest Laboratory, October 1984.

In PNL-4621 Final, facilities at the Los Alamos National Laboratory were discussed, including the Los Alamos Meson Physics Facility (LAMPF). These discussions were based on 1981 radionuclide emissions as reported by DOE in DOE's "Effluent Information System, EPA Release Point Analysis Information Report for Calendar Year 1981." In 1983, however, DOE reported substantially higher emissions from L.AMPF, suggesting that a further review of possible additional emission control technology at the LAMPF might be appropriate. Accordingly then, this addendum was prepared for the purpose of reexamining radionuclide emission control technology at the LAMPF in order to determine whether or not better alternatives exist.

In PNL-4621 Fina 1, References 2a, 2b, and 2c at the end of Section 1 were inadvertently omitted. These references appear in an errata sheet at the end of this addendum. 


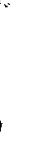




\section{SUMMARY}

The purpose of this addendum is to provide information to the U.S. Environmental Protection Agency on existing technology at the Los Alamos Meson Physics Facility (LAMPF) for the control of radionuclide emissions to the atmosphere and on possible additional control technology that could further reduce these emissions.

Emission of short-lived air activation products from the LAMPF in 1983 increased substantially over 1981 and 1982 to a total of 464 thousand curies, resulting in a maximum site boundary dose calculated by the U.S. Department of Energy to be 48.4 mil1irem per year. Existing control technology consists of an air collection system and a stack which provides for some holdup and decay of the short-1ived isotopes produced at the beam stop and in target areas. Modifications are presently being installed at the beam stop to improve experimental conditions, which will also reduce the formation of air activation products at the beam stop and provide some additional holdup time. Also under consideration is the installation of a new air tunnel and stack, at a different location, to further increase holdup time of air activation products produced at the beam stop. Alternate control technology suggested by the Pacific Northwest Laboratory includes a holdup tank system to reduce LAMPF stack emissions. The estimated costs and efficiencies in reducing radionuclide emissions are discussed. 
6

.

. 


\section{CONTENTS}

FOREWORD

SUMMARY

1.0 LOS ALAMOS MESON PHYSICS FACILITY $\ldots \ldots \ldots \ldots \ldots \ldots \ldots \ldots \ldots \ldots \ldots$

1.1 INTRODUCTION $\ldots \ldots \ldots \ldots \ldots \ldots \ldots \ldots \ldots \ldots \ldots \ldots \ldots \ldots \ldots \ldots$

1.2 EXISTING EMISSION CONTROL TECHNOLOGY AT LAMPF $\ldots \ldots \ldots \ldots \ldots$.

1.3 POTENTIAL ADDITIONAL EMISSION CONTROL TECHNOLOGY

AT LAMPF ................................... 5

1.3.1 Emission Control Technology Proposed by LANL ....... 5

1.3.2 Emission Control Technology Proposed by PNL ........ 9

1.3.3 Comparison of Alternate Technologies ............ 11

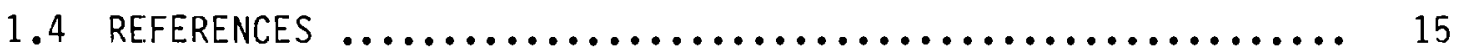

ERRATA: PAGE 1.14 of PNL-4621 FINAL $\ldots \ldots \ldots \ldots \ldots \ldots \ldots \ldots \ldots \ldots \ldots \ldots \ldots \ldots \ldots \ldots$ 
. 


\section{FIGURES}

1 Effect of Holdup Time on Emissions from the LAMPF Stack ........ 12

2 Holdup Tank Volume as a Function of the Holdup Time .......... 13

3 Estimated Capital Costs for Holdup Tanks of Various Sizes ...... 14

\section{TABLES}

1 Airborne Releases from the LAMPF Stack $\ldots \ldots \ldots \ldots \ldots \ldots \ldots \ldots \ldots \ldots$

2 Estimated Maximum Boundary and Individual Doses from Airborne Radioactivity ................................ 4

3 Effect of Holdup Time on the Release of Air Activation Products from the Proposed Stack Serving the LAMPF Beam Stop ........... 7

4 Effects of a $9,300 \mathrm{~m}^{3}$ Holdup Tank on the Emissions from the

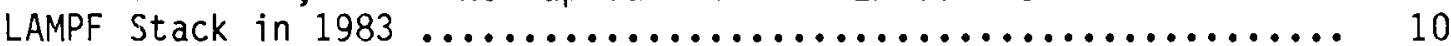

5 Capital Cost Estimate for a $9,300 \mathrm{~m}^{3}$ Holdup Tank System ........ 10

6 Comparison of Alternate Technologies for Reducing Site Boundary Doses Resulting from LAMPF Emissions ..................... 15 
 


\subsection{LOS ALAMOS MESON PHYSICS FACILITY}

The Clinton P. Anderson Los Alamos Meson Physics Facility (LAMPF) in the TA-53 area of the Los Alamos National Laboratory (LANL) consists primarily of a proton linear accelerator approximately $800 \mathrm{~m}$ long designed to produce an 800 MeV proton beam with an average intensity of one milliampere. The proton beam, and secondary particles produced when the energetic protons strike a target, are used in a wide variety of experimental programs. Fields of investigation include medium energy nuclear physics, biophysics, radiochemistry, and cancer therapy.

Interaction of the proton beam and the secondary particles with air produce air activation products. These activation products are discharged to the atmosphere from the LAMPF main stack and are the principal contributors to the offsite dose resulting from LANL operations.

An evaluation of emission control technology at the LAMPF was included in a study carried out at the Pacific Northwest Laboratory (PNL) for the Environmental Protection Agency (EPA) in 1983. (1) The present report is an update of the original work and is based on the most recent (1983) emissions data available from LANL. (2)

\subsection{INTRODUCTION}

During recent years over 95\% of the site boundary dose at LANL has been attributed to the release of air activation products from the LAMPF. The air activation products are sources of gamma radiation through positron-electron annihilation reactions. Air activation products are generated at the primary beam stop and at several target areas. The distribution of radioactive species produced at the various areas is not known, but it is assumed that at least $50 \%$ of the air activation products are formed at the beam stop. Total emissions of air activation products from the LAMPF are primarily dependent on the beam current used in the particle accelerator and on the total duration of the accelerator operating cycles. Total emissions in 1983 (about 464,000 Ci) were higher than in previous years because of the use of a higher beam current in 
the accelerator. Emissions in future years could increase significantly if beam currents are further increased and/or if the accelerator operating time is increased.

Studies are underway at LANL to develop methods for reducing radioactive emissions from the LAMPF. Modifications underway or under consideration include (1) improvements at the beam stop that will reduce the formation of air activation products, and will increase the holdup time for radioisotopes formed at the beam stop prior to release, and (2) installation of a new air tunnel and stack, at a different location, for discharging the radioactive air from the beam stop. Improvements at the beam stop began in the last quarter of 1984 .

In PNL's original study for the EPA, (1) the use of a holdup tank system to reduce LAMPF stack emissions was recommended. The holdup tank system is reevaluated here using 1983 stack emissions data.

Comparing the effectiveness of the LANL modifications with the PNL holdup tank system is difficult because the LANL modifications are directed only at the beam stop area, from which at least half, but not all, of the air activation products arise (the exact percentage is not known). The PNL holdup tank system is, on the other hand, designed to accept air activation products from the other target areas as well as from the beam stop, as is the case with LANL's existing system.

\subsection{EXISTING EMISSION CONTROL TECHNOLOGY AT LAMPF}

Nuclear reactions with air in the various target areas and primary beam stop at LAMPF cause the formation of the air activation products carbon-11, nitrogen-13, oxygen-14, and oxygen-15. These air activation products are all positron emitters, and are the source of gamma radiation from the formation of two $0.511 \mathrm{MeV}$ photons through positron-electron annihilation reactions. Neutron reactions with air at LAMPF also form argon-41 which emits a $1.29 \mathrm{MeV}$ gamma with a $99 \%$ yield.

A major fraction of the air activation products and argon-41 produced at LAMPF is generated at the beam stop, although the ratio will vary depending 
on accelerator operating conditions and other factors. The distribution of radioactive species between the various generation points is not known.

The radioactive air produced in the various areas at the LAMPF is pres ently collected and discharged through the LAMPF main stack. The air collection system provides some holdup for decay of the radioactive species prior to discharge but the exact holdup time is not known. Air flow to the LAMPF stack is currently about $15,100 \mathrm{cfm}\left(428 \mathrm{~m}^{3} / \mathrm{min}\right)$. The air flowing to the stack is routinely analyzed to determine the radioactive emissions from the stack.

Table 1 gives the LAMPF stack emission data for the years 1981-1983. The half-lives for the air activation products are also shown in Table 1. Airborne emissions from the LAMPF stack increased substantially in 1983 compared to releases in earlier years. Changes in the isotopic composition of the emissions were also observed. The increase in emissions for 1983 is attributed primarily to the use of higher beam currents in the particle accelerator.

The maximum site boundary dose and the maximum individual dose at the boundary from all LANL operations for the years 1981-1983 are given in Table 2. Over 95\% of each of the doses is attributed to the emission of air activation products from LAMPF. (2) The doses given in Table ? were estimated from direct radiation measurements obtained using networks of thermoluminescent dosimeters (TLD). The TLD networks provide a measure of the radiation resulting from the LAMPF releases, in addition to cosmic and terrestrial background radiation.

In Table 2 the maximum individual doses reported for 1982 and 1983 are much larger fractions of the maximum boundary doses than was the case for 1981. This is because a higher occupancy factor was used in calculating the maximum individual doses for 1982 and 1983 than was used for 1981 (168 hours per week versus 40 hours per week). A shielding factor of $30 \%$ was used in each case to calculate the maximum individual doses.

In 1983 gamma radiation from the carbon-11 and oxygen-15 accounted for almost all of the dose attributed to LAMPF emissions ( $>95 \%$ of the total dose), 
TABLE 1. Airborne Releases from the LAMPF $\operatorname{Stack}(2,3,4,5)$

\begin{tabular}{|c|c|c|c|c|}
\hline Radionuclide & $\begin{array}{l}\text { Ha If }-L \text { ife } \\
(\min ) \\
\end{array}$ & $\frac{\text { Activity }}{1981}$ & $\frac{\text { Released }}{1982}$ & $\frac{(\mathrm{Ci} / \mathrm{yr})}{1983}$ \\
\hline Carbon-11 & 20.3 & 127,200 & 90,000 & 75,600 \\
\hline Nitrogen-13 & 10.0 & 24,730 & 18,000 & 19,830 \\
\hline $0 x y$ gen -14 & 1.2 & -- & -- & 10,610 \\
\hline 0xygen -15 & 2.03 & 200,300 & 142,300 & 353,210 \\
\hline Argon -41 & 109.8 & 1,060 & 700 & 1,840 \\
\hline $\mathrm{Au}-192+\mathrm{Hg}-195$ & -- & -- & 180 & 2,640 \\
\hline Total & & 353,290 & 251,180 & 463,730 \\
\hline
\end{tabular}

TABLE 2. Estimated Maximum Boundary and Individual (2) Doses from Airborne Radioactivity

\begin{tabular}{ccc} 
Year & $\begin{array}{c}\text { Estimated Maximum } \\
\text { Boundary Dose } \\
\text { (mrem/yr) }\end{array}$ & $\begin{array}{c}\text { Estimated Maximum } \\
\text { Individual Dose } \\
\text { (mrem/yr) }\end{array}$ \\
\cline { 2 - 3 } 1981 & 17 & 5 \\
1982 & 12 & 8.4 \\
1983 & 48.4 & 34.4
\end{tabular}

(a) Estimated maximum boundary dose is the dose from Laboratory operations (excluding dose contributions from cosmic, terrestrial, medical diagnostics, and other non-Laboratory sources) to a. hypothetical individual at the Laboratory boundary where the highest dose rate occurs. It assumes the individual is outdoors at the Laboratory boundary continuously ( 24 hours a day, 365 days a year).

(b) Estimated maximum individual dose is the dose from Laboratory operations (excluding dose contributions from cosmic, terrestrial, medical diagnostics, and other non-Laboratory sources) to an individual at or outside the Laboratory boundary where the highest dose rate occurs and where there is a person. It takes into account occupancy and shielding factors (for 1981 an occupancy factor of 40 hours per week was used, while 168 hours per week was used for 1982 and 1983). 
in approximately equal proportions. (a) The other air activation products and the gold-192 and mercury-195 released from the LAMPF stack did not contribute significantly to the site boundary doses in 1983.

From the data in Tables 1 and 2, it is difficult to correlate site boundary dose data for the years 1981 to 1983 with LAMPF stack emissions. The maximum boundary doses for 1981 and 1982 are proportional to the total LAMPF stack emissions for those years. No such correlation exists between the maximum boundary dose and stack emissions for 1983. LANL attributes the sharp increase in the maximum boundary dose in 1983 to:

- the increase in the total airborne emissions from LAMPF

- a shift in the isotopic composition of the emissions

- a slight change in meteorological conditions.

If the carbon-11 and oxygen-15 each account for about half of the site boundary dose attributed to LAMPF emissions (which in turn accounts for over $95 \%$ of the total dose), the first two factors listed above would not account for the increase in the maximum boundary dose observed in 1983. This would further indicate that the slight changes in meteorological conditions observed in 1983 had a large effect on the maximum site boundary dose for 1983.

\subsection{POTENTIAL ADDITIONAL EMISSION CONTROL TECHNOLOGY AT LAMPF}

The radioactive emissions from the LAMPF stack in 1983 resulted in boundary doses which could be reduced. In this section methods are evaluated for reducing the 1983 emissions by amounts that would reduce the maximum boundary dose of 48 mrem per year reported in 1983 by 25\% to 75\% (to 36 or $12 \mathrm{mrem} / \mathrm{yr}$, respectively).

\subsubsection{Emission Control Technology Proposed by LANL}

Studies are now underway at LANL to develop methods for reducing the radioactive emissions from LAMPF. Engineering design modifications underway or under consideration include:

(a) R. Dvorak, LANL, personal communication (1984). 
- installation of improved experimental arrangements at the beam stop which will also reduce the formation of air activation products and increase the holdup time of the radioisotopes formed at the beam stop prior to discharge

- installation of a new delay tunnel and a new stack at a different location for discharging the air activation products from the beam stop.

Only those air activation products generated at the beam stop would be affected by these measures. Adding the necessary 300 to $400 \mathrm{ft}$ of ducting to control releases from the target area is not now under consideration. The overall effectiveness of these changes in reducing LAMPF emissions will depend primarily on the fraction of the total emission which is generated at the beam stop. This amount is not known but it is assumed to be greater than $50 \%$. (a)

Modifications currently underway at the beam stop should result in a marked decrease in the formation and release of the air activation products at the beam stop. It is estimated that these modifications will affect a $50 \%$ to $80 \%$ reduction in the generation of the radioactive species. (a) Work on the modifications began in the fourth quarter of 1984. The cost of these modifications is expected to be between $\$ 1$ and 2 million, but the amount attributed directly to reduction of formation and release of an activation products must be estimated as less than half of this amount.

LANL is also considering providing additional holdup time for decay of the 1 , radioisotopes generated at the beam stop prior to discharge. This would be accomplished by discharging the activated air from the beam stop through a new stack. The air would be delivered to the stack through an $8 \mathrm{ft}$ diameter underground tunnel that is $2,000 \mathrm{ft}$ long. The use of two parallel $8 \mathrm{ft}$ diameter tunnels is also being considered. The tunnel(s) would be covered with $4 \mathrm{ft}$ of dirt for shielding purposes. Air flow from the beam stop to the stack would be approximately $5,000 \mathrm{cfm}\left(142 \mathrm{~m}^{3} / \mathrm{min}\right)$. The single tunnel and dual tunnel systems would provide additional holdup times of 20 and 40 minutes, respectively.

(a) R. Dvorak, LANL, personal communication (1984). 
The costs of the two systems including construction of a new stack are estimated by LANL to be $\$ 1.1$ million and $\$ 1.6$ million (in 1984 dollars). These figures do not include the cost of the beam stop modifications. Table 3 shows what effect the additional holdup times provided by the one or two tunnel system would have on the air activation products generated at the beam stop. The data are presented as fractions because the actual amounts of air activation products generated in the beam stop are not known.

The air activation products carbon-11 and oxygen-15 were the principal contributors to the site boundary doses in 1983 (in about equal proportions). From Table 3 it can be seen that either tunnel system would be effective in reducing oxygen-15 emissions from the beam stop stack to low levels. The effect on carbon-11 emissions would be less dramatic but emissions of this nuclide from the beam stop would still be reduced by factors that would reduce the dose from the beam stop by about $50 \%$ to $75 \%$.

The use of a new stack to discharge air activation products generated at the beam stop would affect the atmospheric dispersion of the emissions. This in turn would affect site boundary doses. The proposed site for the new stack would be selected within the options available so as to provide the largest

TABLE 3. Effect of Holdup Time on the Release of Air Activation Products from the Proposed Stack Serving the LAMPF Beam Stop

Fraction of the Radionuclide Generated at the Beam Stop Released to the Atmosphere Single Tunnel Dual Tunnel

Radionuclide Carbon 11

Nitrogen -13

0xygen -14

0 xygen -15

Argon-41
(20 min. additional holdup time) 0.505

0.25

$9.5 \times 10^{-6}$

0.00108

0.885
(40 min. additional holdup time)

0.255

0.0625

$9.09 \times 10^{-11}$

$1.18 \times 10^{-6}$

0.775 
possible reduction in the site boundary dose under normal meteorological conditions. No estimate of the effect of dispersion is presented here.

The modifications and additions currently under consideration at LANL should have little effect on the release of the air activation products generated at LAMPF sites other than the beam stop, i.e., target areas. The radioactive air from target areas would still be collected using the existing system and discharged from the existing LAMPF stack. The air flow to the existing LAMPF stack would probably be somewhat smaller than the current airflow because it would no longer contain the air from the beam stop.

The reduced airflow to the existing stack would increase the holdup time somewhat for the contained air activation products, but the overall effect is difficult to estimate because the holdup time for the existing system under normal operating conditions is not known. It is expected, however, that the reduced airflow to the LAMPF stack would have only a slight effect on carbon-11 emissions but could produce a significant reduction in oxygen-15 emissions.

Because of the many uncertainties involved it is difficult to estimate what overall effect the various modifications planned or proposed by LANL would have on total emissions from LAMPF. For a worst case situation where only beam stop modifications are considered, and

- only $50 \%$ of the air activation products generated at LAMPF are formed at the beam stop, and

- beam stop modifications effect only a $50 \%$ reduction in the air activation products formed at the beam stop,

the overall effect would be no more than a $25 \%$ reduction in total emissions from the existing LAMPF stack. Because no additional time delay occurs in this situation, the improvements would not be adequate to reduce the maximum boundary dose by the desired $50 \%$ to $75 \%$.

Under more favorable conditions of $80 \%$ production of air activation products at the beam stop, $50 \%$ reduction of formation of air activation products at the beam stop, and installation of a dual delay tunnel and new stack, total LAMPF emissions could be reduced by an amount that would reduce the boundary dose by approximately $75 \%$, to $12 \mathrm{mrem} / \mathrm{yr}$. Greater reductions are 
unlikely unless a larger fraction $(>80 \%)$ of the air activation products is generated at the beam stop.

It appears reasonable that if all of the changes being considered by LANL are implemented the maximum boundary dose could be reduced by at least $50 \%$. A more detailed analysis is needed, however, to determine if the $75 \%$ dose reduction postulated above is possible. It is very likely that some treatment of the air activation products formed outside the beam stop will be necessary to obtain a $75 \%$ reduction in the dose.

\subsubsection{Emission Control Technology Proposed by PNL}

In the original study for the EPA by PNL, (1) the use of a holdup tank system was proposed to reduce emissions from the LAMPF stack. The system would handle all of the radioactive air produced at the LAMPF. Based on an airflow rate to the stack in 1981 of $480 \mathrm{~m}^{3} / \mathrm{min}(=\sim 17,000 \mathrm{cfm})$, a tank with a volume of $9,300 \mathrm{~m}^{3}$ (30 m diameter $\times 13.2 \mathrm{~m}$ high) provides a holdup time of 19.4 minutes. Assuming perfect mixing in the holdup tank, the system would reduce total stack emissions (based on 1981 discharge levels) from 353,000 $\mathrm{Ci} / \mathrm{yr}$ to $73,000 \mathrm{Ci} / \mathrm{yr}$. The system would reduce carbon-11 emissions from 127,200 to $65,600 \mathrm{Ci} / \mathrm{yr}$ and the oxygen-15 from 200,300 to $270 \mathrm{Ci} / \mathrm{yr}$. The estimated cost for the $9,300 \mathrm{~m}^{3}$ tank system (in 1983 dollars) was about $\$ 4.3$ million.

Because the isotopic composition of radionuclides released from the LAMPF stack in 1983 was different from that released in 1981, and because the airflows to the stack were different, the holdup tank system proposed in the initial study would have a different effect on 1983 releases from that calculated for the 1981 releases. Based on the lower 1983 airflow to the LAMPF stack, the $9,300 \mathrm{~m}^{3}$ tank would provide a holdup time of 21.7 minutes. Table 4 shows what effect this holdup time would have on the 1983 stack emissions.

Total emissions (neglecting $\mathrm{Au}-192$ and $\mathrm{Hg}-195)$ from the stack would be reduced from $461,100 \mathrm{Ci} / \mathrm{yr}$ to about $42,200 \mathrm{Ci} / \mathrm{yr}$. If it is assumed that carbon-11 and oxygen-15 are the principal and equal contributors to the maximum boundary dose, use of the $9,300 \mathrm{~m}^{3}$ holdup tank would reduce the maximum boundary dose from the 48.4 mrem per year reported in 1983 to about 12 mrem per year, which corresponds to a $75 \%$ reduction. The capital cost for the $9,300 \mathrm{~m}^{3}$ 


\begin{tabular}{|c|c|c|c|}
\hline \multirow[b]{2}{*}{ Radionuclides } & \multicolumn{3}{|c|}{$\begin{array}{l}\text { Effects of a } 9,300 \mathrm{~m}^{3} \text { Holdup Tank }(\mathrm{a}) \\
\text { on the Emissions from the LAMPF Stack } \\
\text { in } 1983\end{array}$} \\
\hline & $\begin{array}{c}1983 \text { Release } \\
(\mathrm{Ci} / \mathrm{yr}) \\
\end{array}$ & $\begin{array}{l}\text { Holdup Time } \\
\text { in Half-Lives } \\
\end{array}$ & $\begin{array}{l}\text { Release After } \\
\text { Holdup ( } \mathrm{C} / \mathrm{yr}) \\
\end{array}$ \\
\hline Carbon-11 & 75,600 & 1.07 & 36,000 \\
\hline Nitrogen-13 & 19,830 & 2.17 & 4,400 \\
\hline 0xygen-14 & 10,610 & 18.1 & 0.04 \\
\hline 0xygen-15 & 353,210 & 10.7 & 214 \\
\hline Argon-41 & 1,840 & 0.198 & 1,600 \\
\hline Total & 461,090 & & 42,214 \\
\hline
\end{tabular}

(a) At the 1983 airflow rate a $9,300 \mathrm{~m}^{3}$ tank would provide about 21.7 minutes of holdup time.

holdup tank system was reestimated to allow for inflation. The new cost for the system in 1985 dollars is still about $\$ 4.3$ million. The cost breakdown for the system is shown in Table 5 .

TABLE 5. Capital Cost Estimate for a $9,300 \mathrm{~m}^{3}$ Holdup Tank System (in 1985 dollars)

\begin{tabular}{|c|c|}
\hline Item & Cost $(\$ K)$ \\
\hline Carbon Steel Tank, Installed (Vol. 9, 300 $\left.\mathrm{m}^{3}\right)$ & 1,720 \\
\hline Compressor, Piping, Instrumentation, Building & 670 \\
\hline Concrete Pad & 260 \\
\hline Site Preparation & 4.0 \\
\hline Subtotal - Direct Construction Costs & 2,690 \\
\hline Architect - Engineering Services (15\%) & 400 \\
\hline Subtotal & 3,090 \\
\hline Contingency $(40 \%)$ & $\underline{1,240}$ \\
\hline Total Facility Cost & 4,330 \\
\hline
\end{tabular}


One factor not considered in detail in evaluating the holdup tank system is the availability of space for locating the tank. A lack of accessible space near the LAMPF main stack could increase the cost of the system significantly.

By reducing the holdup time for the tank system to about six minutes, the 1983 maximum boundary dose would be reduced by $50 \%$. A six minute holdup time would require a tank volume of about $2,600 \mathrm{~m}^{3}$. The capital cost for a $2,600 \mathrm{~m}^{3}$ tank system (in 1985 dollars) was estimated from the cost for the $9,300 \mathrm{~m}^{3}$ tank system using the eight-tenths power of the size ratio. The estimated capital cost for the smaller system is $\$ 1.55 \mathrm{million}$. Since the holdup tank system would handle all of the radioactive air generated at the LAMPF (which is presently handled by the existing LAMPF stack), the reduction in total emissions obtainable is determined by the tank size. Figure 1 shows how the stack emissions of the two critical radioisotopes carbon-11 and oxygen-15 would vary with the holdup time provided by the tank system. From Figure 1 the holdup time required to obtain a given reduction in carbon-11 and oxygen-15 emissions can be determined. The tank size needed to provide the required holdup time, based on the 1983 air flow to the LAMPF stack, can then be determined from Figure 2. Figure 3 shows the estimated capital cost (in 1985 dollars) for the system as a function of the tank volume required. The capital costs for tanks of varying sizes were estimated from the cost of the $9,300 \mathrm{~m}^{3}$ tank (Table 5) using the eight-tenths power of the tank size ratio.

\subsubsection{Comparison of Alternate Technologies}

It is difficult to compare the holdup tank system recommended by PNL with the modifications being proposed by LANL in terms of their effectiveness in reducing LAMPF emissions and site boundary doses. The holdup tank system, if it could be installed, has the advantage that it would handle all of the contaminated air generated at the LAMPF. The reductions in stack emissions and boundary doses obtainable would only be limited by tank size and available funding. The modifications proposed by LANL should cost less to implement than the holdup tank system but their effectiveness in reducing LAMPF emissions and site boundary doses is less well defined because they affect only the radionuclides generated at the beam stop. Estimates of the effectiveness of the various options and their associated costs, are summarized in Table 6 . If only 


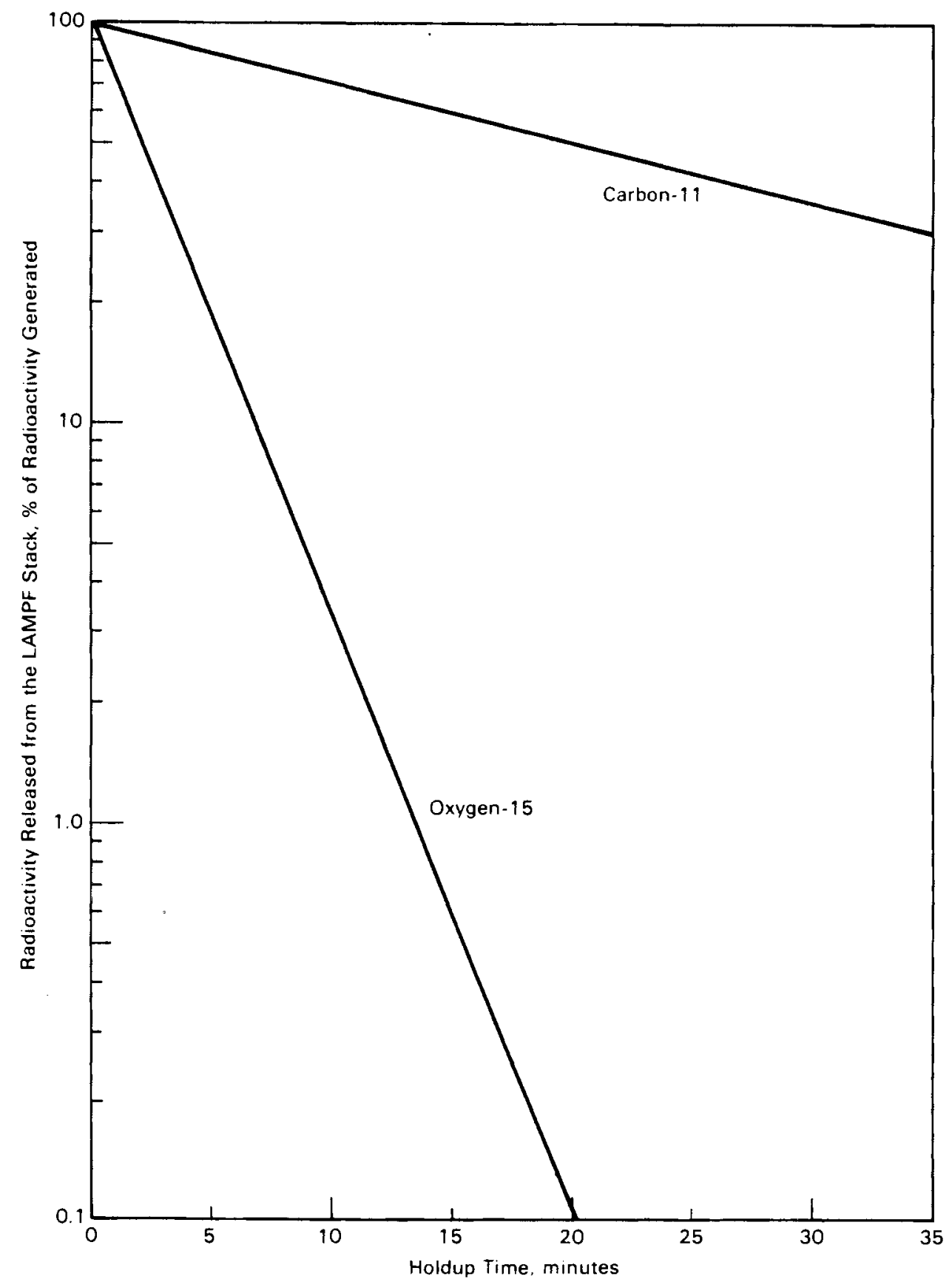

FIGURE 1. Effect of Holdup Time on Emissions from the LAMPF Stack 


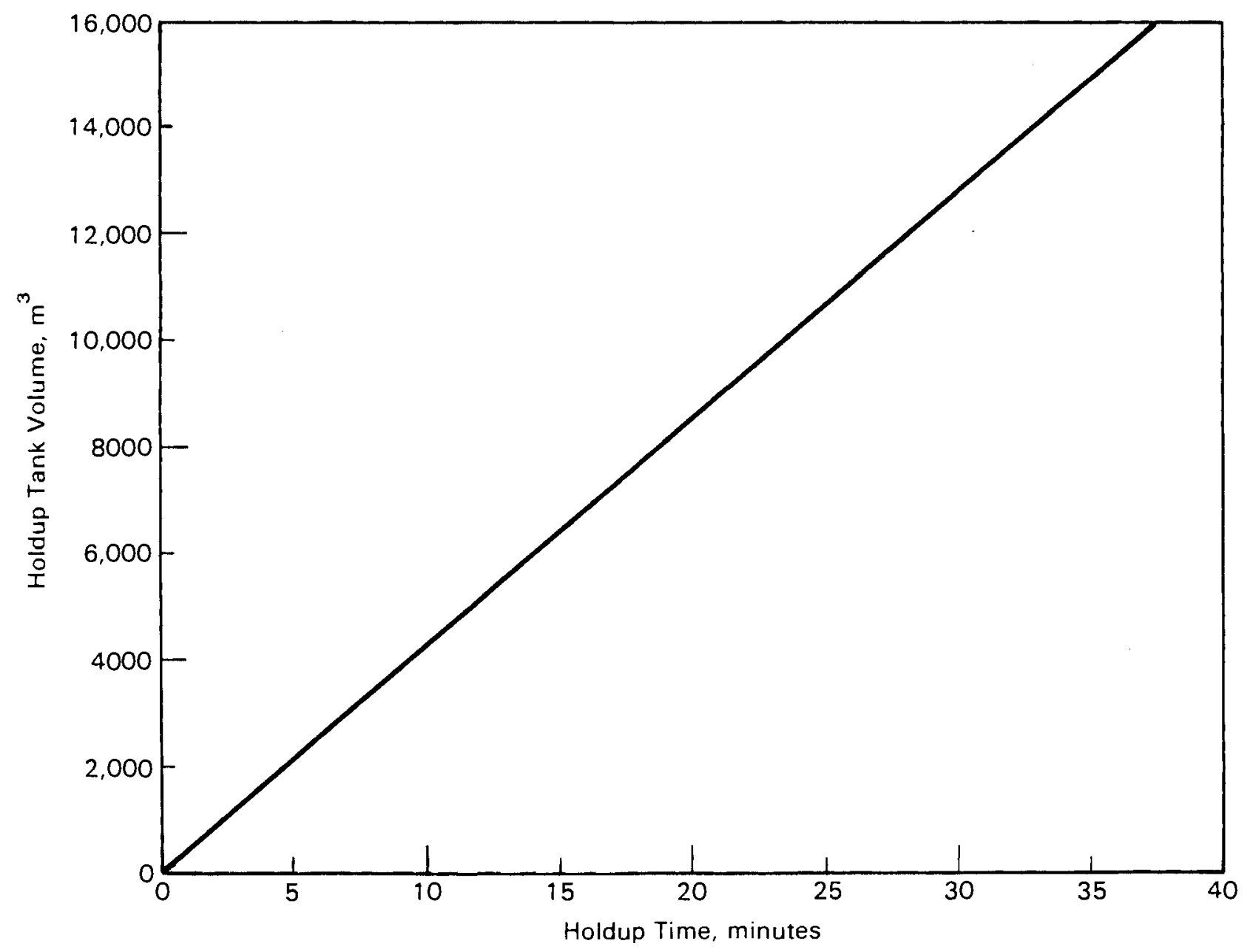

FIGURE 2. Holdup Tank Volume as a Function of the Holdup Time (tank volume is based on 1983 air flow to the LAMPF stack of $15,100 \mathrm{cfm}$ ) 


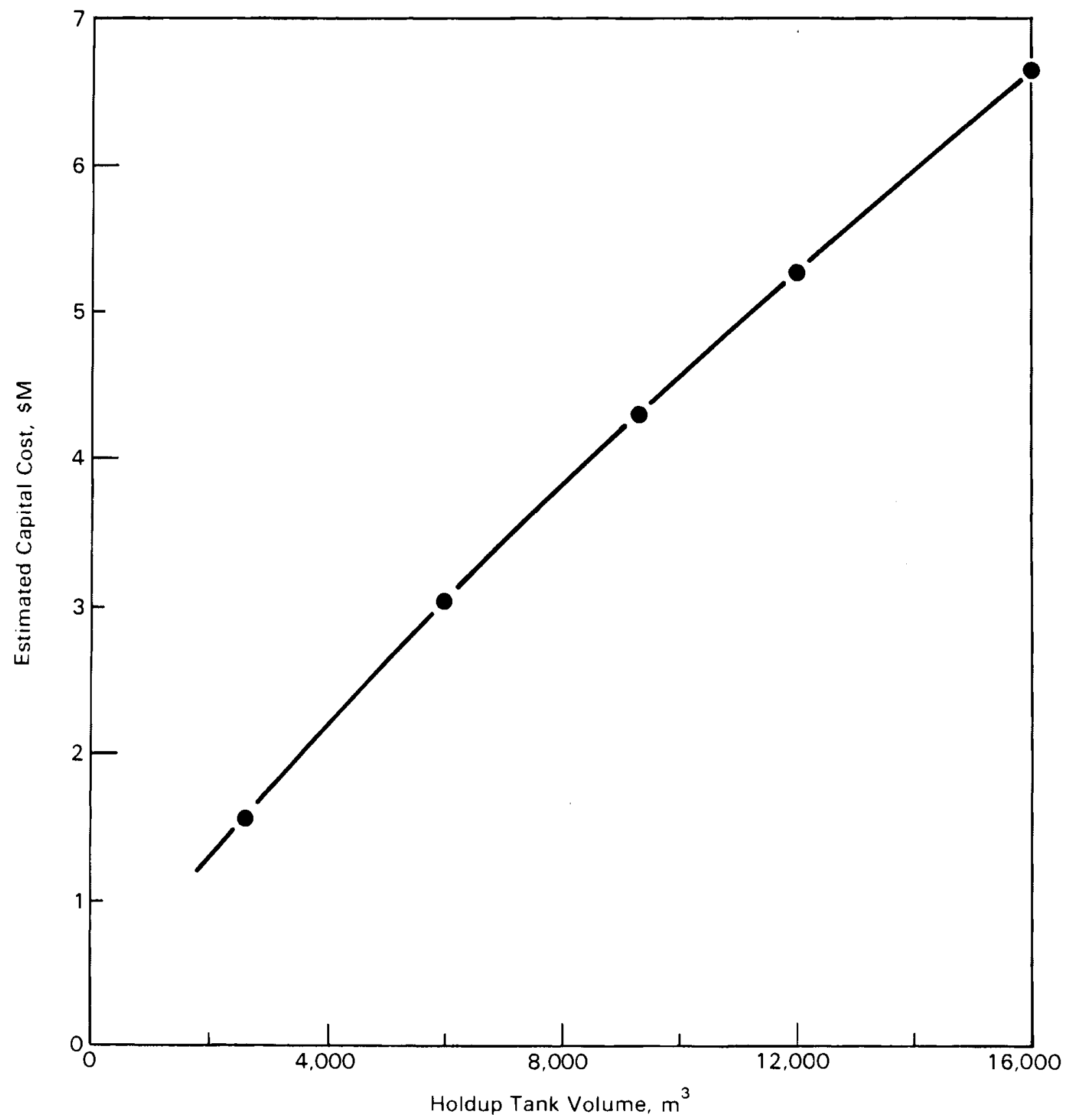

FIGURE 3. Estimated Capital Costs for Holdup Tanks of Various Sizes (in 1985 dollars) 
TABLE 6. Comparison of Alternate Technologies for Reducing Site Boundary Doses Resulting from LAMPF Emissions

\begin{tabular}{|c|c|c|c|}
\hline & & $\begin{array}{c}\text { Estimated } \\
\text { Dose Reduction (a) } \\
(\%) \\
\end{array}$ & Cost (1985 \$K) \\
\hline & No Action & 0 & 0 \\
\hline & $\begin{array}{l}\text { LANL Options } \\
\text { A. Beam Stop Modifications }\end{array}$ & $25(b)$ & (c) \\
\hline & $\begin{array}{l}\text { B. Beam Stop Modifications } \\
\text { Plus New Dual Tunnel } \\
\text { and Stack }\end{array}$ & $75^{(d)}$ & (c) $+1,600$ \\
\hline & PNL Option-Holdup Tank & $\begin{array}{l}25 \\
50 \\
75\end{array}$ & $\begin{array}{r}700 \\
1,600 \\
4,300\end{array}$ \\
\hline
\end{tabular}

(a) Based on 1983 LAMPF Operations.

(b) Assumes $50 \%$ of the radionuclides are generated at the beam stop and that the modifications reduce production of radionuclides by $50 \%$.

(c) The cost of beam ste modifications is estimated to be between $\$ 1$ and $\$ 2$ million, but less than half of this cost can be assigned to reducing air activation.

(d) Assumes $80 \%$ of the radionuclides are generated at the beam stop and the modifications reduce production of radionuclides by $50 \%$.

moderate reductions in boundary doses are acceptable $(<50 \%)$ then the modifications proposed by LANL are probably the preferred alternative. If greater reductions in boundary doses are needed, then serious consideration should be given to the use of a holdup tank system.

\subsection{REFERENCES}

1. Moore, E.B. (Project Manager). 1984. Control Technology for Radioactive Emissions to the Atmosphere at U.S. Department of Energy Facilities, PNL4621 (Final). Pacific Northwest Laboratory, Richland, Washington.

2. Environmental Surveillance Group. 1984. Environmental Surveillance at Los Alamos During 1983, LA-10100- ENV. Los Alamos National Laboratory, Los Alamos, New Mexico.

3. U.S. Department of Energy Effluent Information System, EPA Release Point Analysis Report for Calendar Year 1981. 
4. Environmental Surveillance Group. 1983. Environmental Surveillance at Los Alamos During 1982, LA-9762- ENV. Los Alamos National Laboratory, Los ATamos, New Mexico.

5. Environmental Surveillance Group. 1982. Environmental Surveillance at Los Alamos During 1981, LA-9349-ENV. Los Alamos National Laboratory, Los Alamos, New Mexico. 
ERRATA: PAGE 1.14 of PNL-4621 FINAL

1. 72 United States Code 7401 et seq.

2. Federal Register, December 27, 1979 (44 FR 76738).

2a. Federal Register, April 6, 1983 (48 FR 15076).

2b. E. B. Moore (Project Manager), Control Technology for Radioactive Emis sions to the Atmosphere at U.S. Department of Energy Facilities. PNL-4621 Draft. Pacific Northwest Laboratory, March 1983.

2c. U.S. Environmental Protection Agency, Background Information Document [on] Proposed Standards for Radionuclides. EPA 520/1-83-001 Draft. March 1983.

3. U.S. Department of Energy Effluent Information System, EPA Release Point Analysis Report for Calendar Year 1981.

4. Summary of Annual Environmental Reports for CY-1980, Department of Energy Nuclear Sites. U.S. DOE, DOE/EP0-0038, August 1982.

5. C. G. Welty, et al. "The DOE Program for Control of Radioactive Releases to the Environment," In Proceedings of the Second U.S. DOE Environmental Control Symposium. CONF 800334, Vol. 2, p. 477ff, June 1980.

6. "Effluent and Environmental Monitoring and Reporting," U.S. Atomic Energy Commission Manual, Chapter 0513, 1973.

7. A Guide for Environmental Radiological Surveillance at ERDA Installations, ERDA 77-24, Energy Research and Development Administration, March 1977; revised as A Guide for Radiological Surveillance of U.S. Department of Energy Installations, DOE/EP-0023, JuTy 1981. 
$=$
$\therefore$
$\therefore$
$\therefore$ 